\title{
Mentalizing in Children with Type 1 Diabetes and Their Mothers
}

Stefanella Costa-Cordella ${ }^{1}$, Patrick Luyten ${ }^{1,2}$, Diego Cohen $^{3}$, Francisca Mena $^{4}$, and Peter Fonagy ${ }^{1}$

${ }^{1}$ University College London

${ }^{2}$ University of Leuven

${ }^{3}$ Universidad de Buenos Aires

${ }^{4}$ Fundación Diabetes Juvenil de Chile

Short title: Mentalizing and Diabetes

Corresponding author: Stefanella Costa-Cordella

stefanella.cordella.15@ucl.ac.uk

in press: Development and Psychopathology 


\begin{abstract}
Studies suggests that the relationship between psychosocial well-being and type 1 diabetes (T1D) is bidirectional, with T1D typically having a negative influence on psychological functioning, which in turn negatively affects the course of T1D. Here, we investigate the potential role of the capacity for mentalizing, or reflective functioning, in children and their mothers in diabetes control. We tested differences in mentalizing as assessed by the Reflective Functioning Scale in two groups of mother-son dyads with good (GDC) versus poor (PDC) diabetes control. Fifty-five boys (8-12 years old) and their mothers were recruited from the Juvenile Diabetes Foundation in Santiago, Chile. Mothers were interviewed with the Parental Development Interview and children with the Child Attachment Interview, and both were scored for reflective functioning using the Reflective Functioning Scale. Self-report measures of stress and diabetes outcomes were completed by mothers and children, and levels of glycated hemoglobin (HbA1c) were assessed as an index of diabetes control. Results showed that both maternal and child reflective functioning were higher in the GDC than the PDC group and were negatively correlated with $\mathrm{HbA1c}$ in the total sample. Our findings suggest an important role for mentalizing in diabetes outcomes, but further prospective research is needed.

Keywords: type 1 diabetes, child mentalizing, reflective functioning, parental mentalizing.
\end{abstract}


Mentalizing in Children with Type 1 Diabetes and their Mothers

Type 1 diabetes (T1D) is one of the most common autoimmune conditions in children. Population-representative studies suggest an annual increase of 80,000 cases in girls and boys under 15 years old across the world (International Diabetes Federation, 2017). T1D often has a serious impact on the psychosocial well-being of both children and their caregivers, as management of the disease requires considerable changes in the lifestyle of the child, which may put the parent-child relationship under considerable strain (Patterson et al., 2009). Recent years have seen a growing interest in the relationship between T1D and psychosocial well-being. Studies have suggested that this relationship is bidirectional, that is, T1D may negatively affect psychosocial functioning, which in turn may negatively influence the course and prognosis of T1D.

Studies have shown that children with T1D are twice as likely as peers without diabetes to develop mental health problems (Fazeli Farsani et al., 2016). Research has also consistently shown that mental health problems in these children are associated with decreased treatment adherence (i.e., the extent to which children adhere to the treatment regimen) and metabolic control (i.e., the extent to which children's glycemic levels correspond with target levels), which in turn may increase the risk for complications (i.e., retinopathy, nephropathy, and cardiovascular disease). For example, both depression (Kongkaew et al., 2014) and family conflict (Burroughs et al., 1997; La Greca et al., 1995) have been associated with poorer adherence to treatment, while disturbed eating behaviors have been associated with poor diabetes control (Helgeson et al., 2009). 
As noted, T1D may also affect caregivers. For instance, in a prospective study by Landolt et al. (2005) in a sample of 97 parents of children with T1D, $24 \%$ of mothers and $22 \%$ of fathers met full diagnostic criteria for post-traumatic stress disorder immediately after the child's T1D diagnosis. Similarly, elevated levels of stress and anxiety in parents of children with T1D (Horsch et al., 2007; Landolt et al., 2002, 2005; Northam et al., 1996; Streisand et al., 2008), especially in mothers (Hansen et al., 2012; Jönsson et al., 2015; Sullivan-Bolyai, 2003; Wennick \& Hallström, 2007,), have been reported. In turn, parental stress has been shown to be one of the strongest predictors of psychosocial problems in children with diabetes (Drotar, 1997; Hilliard et al., 2011; Kovacs et al., 1997). As a result, there is increasing consensus that developmental factors, including the caregiving environment of the child, are crucial in diabetes control. However, developmental and relational factors remain poorly integrated in current theoretical approaches to T1D in children (Lohan, Morawska and Mitchell, 2015; Daneman \& Daneman, 2012; Ciechanowski, Hirsch, and Katon, 2002).

Contemporary attachment and mentalization-based approaches may provide an important theoretical perspective in this context (Fonagy and Bateman, 2006, 2008; Fonagy and Target, 2006, Luyten and Fonagy, 2016). For instance, there is now good evidence to suggest that attachment plays a key role in the onset and course of somatoform or functional somatic disorders, a group of disorders that has a similarly strong somatic component as T1D (Luyten, Van Houdenhove, Lemma, Target, and Fonagy, 2012, 2013). Indeed, studies have amply shown the key role of attachment in the regulation of stress and arousal in these disorders. From an attachment perspective, somatic problems, such as T1D, represent an important source of conflict and stress for both child and caregiver. Generally speaking, stress responses are triggered by a threat to the individual's survival, initiating physiological processes designed to 
mobilize and reorganize the body's resources for the sake of maintaining bodily integrity. As a result, both physiological and psychological systems are activated in order to attempt to downregulate the stress response and restore bodily allostasis (McEwen, 2007; Picard and McEwen, 2018).

With regard to T1D, the stressful experience mostly comes from within the individual's own body. This threat is also permanent, which means that the individual is confronted with a near-constant activation of the stress response, and thus of the attachment behavioral system. Chronic activation of the stress system is known to be associated with several health problems in the general population (Gunnar and Quevedo, 2007; Muscatell and Eiserberger, 2012; Carroll et al., 2012; Peters, McEwen, and Friston, 2017; Picard and McEwen, 2018). Additionally, in individuals with T1D, stress might cause metabolic dysregulation resulting in negative diabetes outcomes (Hilliard et al., 2016; Lloyd et al., 1999, Konen et al., 1993), directly through the influence of stress hormones on glucose homeostasis, and indirectly by affecting treatment adherence (Hilliard et al., 2016).

As part of the stress response, an individual's attachment system is activated (Bowlby, 1969, 1973; Collins \& Read, 1990; Bartholomew \& Horowitz, 1991; Mikulincer \& Florian, 1995; Fraley \& Shaver, 1998; Mikulincer \& Shaver, 2007). Effective management of stress characteristically involves a process of co-regulation, which takes place within a relationship with an attachment figure (Diamond and Aspinwall, 2003; Luyten et al., 2013; Sbarra and Hazan, 2008). If this process proceeds successfully, the individual achieves a sense of safety, and the attachment system is deactivated. However, co-regulation of stress through reliance on attachment figures is typically impaired if the magnitude or persistence of the threat is such that the usual attachment strategies adopted by the individual are insufficient to down-regulate the 
stress response, in which case secondary attachment strategies (i.e., attachment hyperactivation and deactivation strategies) are activated. Attachment hyperactivation strategies are characterized by demanding attempts to gain relief from others, generally using clinging and claiming behavior (Waller and Scheidt, 2006). The use of attachment deactivation strategies, by contrast, typically involves a negation of attachment needs, affirming autonomy and independence in the face of stress (Cassidy and Kobak, 1988; Mikulincer and Shaver, 2007). Although potentially adaptive in the short term, in the longer term the use of attachment hyperactivation and deactivation strategies results in a chronic hyperactivation of the stress system, particularly the hypothalamicpituitary-adrenal (HPA) axis, the main endocrine system involved in stress regulation, which may lead to serious disruptions in the stress response. This, in turn, produces more stress, creating a second vicious circle that also affects the way the individual's capacity to reflect or mentalize the self (and particularly the bodily self) and others (Luyten and Fonagy, 2016) (Figure 1). 


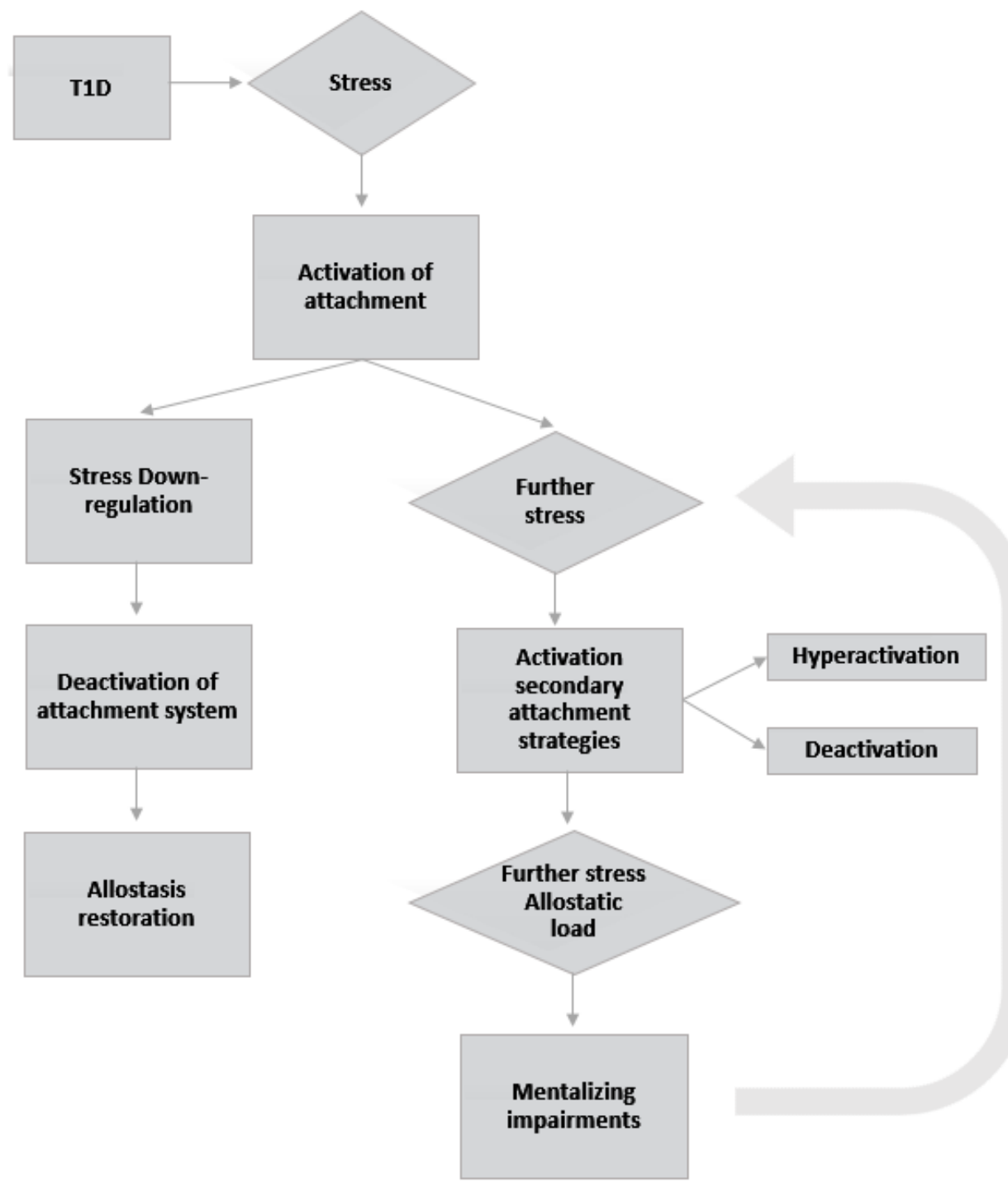

Figure 1. T1D, stress, and attachment mentalizing

Consistent with these assumptions, studies have demonstrated the relevance of attachment in T1D (Turan, Osar, Turan, Ilkova, and Damci, 2003; Bazzazian and Besharat, 2012; Morris et al., 2009; Ciechanowski, Katon, Russo, and Walker, 2001; Ciechanowski et al., 2004). For instance, a population-based study $(N=4,095)$ in adults with T1D and type 2 diabetes (Ciechanowski et al., 2004) found that patients with secure attachment showed better self- 
management and better diabetes outcomes than patients with insecure attachment styles.

Similarly, in another study, these authors found that individuals with T1D with avoidant attachment showed poorer treatment adherence than those with secure or ambivalent attachment styles (Ciechanowksi et al., 2001). Furthermore, studies converge to suggest that chronic somatic disorders may lead to serious impairments and distortions in (embodied) mentalizing (Luyten and Fonagy, 2016; Luyten, Van Houdenhove, Lemma, Target, and Fonagy, 2012, 2013; Koelen, Eurelings-Bontekoe, van Broeckhuysen-Kloth, Snellen, and Luyten, 2014; Schönenberg et al., 2014; Malberg, 2013). Such distortions are, for instance, expressed in a tendency to make catastrophic attributions in response to bodily sensations, in the incapacity to reappraise threatening situations, and in the rigid misinterpretation of others' behaviors. Impairments in (embodied) mentalizing have been consistently demonstrated in other chronic disorders, and there is preliminary evidence to suggest that this is also the case in children with T1D (Moran and Fonagy, 1987; Fonagy and Moran, 1990, 1991, 1993, 1994; Moran, Fonagy, Kurtz, Bolton, and Brook, 1991).

Yet, further research in T1D is clearly needed, not only given the paucity of studies, but also given that little is known about the potential role of parental attachment and mentalizing in explaining the course and prognosis of T1D in children. In this context, there is growing evidence that the caregiver's capacity to think of his/her child in terms of mental states (i.e., parental mentalizing or parental reflective functioning $[R F])$ is linked with the development of affect regulation in the child (Meins, Fernyhough, Fradley, and Tuckey, 2001; Oppenheim and Koren-Karie, 2002; Slade et al., 2005, Zeegers et al., 2017). Parental RF is probably also determined by the child's characteristics. Hence, evocative person-environment correlations 
(Klahr and Burt, 2014) may be involved in the relationship between parental RF and child RF (Luyten, 2015).

\section{The Present Study}

Although there is growing evidence for the role of mentalizing or RF in affect regulation in a number of psychological and somatoform disorders (Luyten and Fonagy, 2016; Fonagy and Luyten, 2009; Luyten et al., 2012; Nolte et al., 2011; Fonagy and Target, 2006), no study to date has simultaneously investigated the role of child and parental RF in T1D.

Therefore, the main purpose of the present study was to compare levels of parental and child RF using state-of-the-art, observer-rated measures in both mothers and male children with T1D. In this study, we specifically focused on mothers and male children, as boys with T1D may be specifically vulnerable to developing psychosocial and medical problems. The prevalence of T1D has been found to be substantially higher in boys than in girls, with a 3:2 ratio (Wandell and Carlsson, 2013; Gale and Gillespie, 2001). Moreover, boys with T1D have been shown to have worse treatment adherence (Naar-King et al 2006), worse metabolic control (Grey, Lipman, Cameron, and Thurber, 1997), and a lower frequency of blood glucose testing (Bearman and La Greca 2002) than girls.

We compared two different groups of boys and their mothers based on their diabetes control as measured by glycated hemoglobin (HbA1c), which is considered the "gold standard" measure of diabetes control (Delamater et al., 2018). Groups were formed based on a median split (see Methods section), with boys in the good diabetes control (GDC) group having HbA1c levels below 7.70, and boys in the poor diabetes control (PDC) group having HbA1c levels above 7.71. These values correspond to international standard cut-off points for defining good 
versus poor diabetes control, with HbA1c levels below 7 considered to reflect GDC, while values above 7.5 have been consistently associated with an increased risk of complications (NICE, 2015; American Diabetes Association, 2017; Lind et al., 2019). Moreover, diabetes-specific quality of life and children's subjective levels of stress were measured using self-report measures.

This is the first investigation, to our knowledge, to examine the role of RF in mothers and children with T1D based on observer rated measures. We expected that (1) mothers and boys in the GDC group would exhibit higher levels of RF than mothers and boys in the PDC; (2) boys in the PDC group would present higher levels of stress than boys in the GDC group; (3) maternal and child RF would be negatively correlated with HbA1c and positively correlated with diabetesspecific quality of life; and (4) children's stress would be negatively correlated with maternal RF, child RF, and diabetes-specific quality of life, and positively correlated with HbA1c.

\section{Method}

\section{Participants and Procedure}

Fifty-five boys aged 8-12 years and their mothers were recruited from the Juvenile Diabetes Foundation of Chile (JDFC; see Table 1 for sociodemographic characteristics of the sample), comprising 28 dyads with GDC (HbA1c <7.70) and 27 dyads with PDC (HbA1c >7.71). Families of children who had been diagnosed with T1D at least 6 months previously were contacted by the institution via e-mail with an invitation letter containing the study details. Families that showed interest were contacted via telephone to schedule an interview session at the JDFC' offices. Approximately $50 \%$ of families who were contacted agreed to participate. An interview session for mothers and boys separately was scheduled to be carried out in the 
foundation's offices, and were interviews were carried out by two trained clinical psychologists. At the end of the interview, participants were asked to complete a series of questionnaires (see below). Mothers were also asked to report the scores for their child's previous three HbAlc measurements, and the mean was used in all analyses. Of the recruited families, $85 \%$ completed both interviews and all questionnaires. One family did not complete the two interviews and was excluded from the analyses. This study was approved by the University College London (UCL) Research Ethics Committee.

\section{Table 1}

Mothers' and Children's Demographic Characteristics as a Percentage (Standard Deviation in Parentheses) per group

\begin{tabular}{lll}
\hline & \multicolumn{2}{c}{ Group } \\
\cline { 2 - 3 } Characteristic & \multicolumn{1}{c}{$\begin{array}{c}\text { PDC } \\
(n=27)\end{array}$} & \multicolumn{1}{c}{$\begin{array}{c}\text { GDC } \\
(n=28)\end{array}$} \\
\hline Mother's educational level & \\
Primary school & 14.8 \\
High school & 33.3 & 32.1 \\
Vocational school & 11.1 & 17.9 \\
College degree & 37 & 35.7 \\
Graduate school & 3.7 & 14.3 \\
Family socioeconomic level & & \\
Poverty & 3.7 & \\
Low middle & 33.3 & 25 \\
Middle & 40.7 & 25 \\
High middle & 7.4 & 7.1 \\
High & 14.8 & 42.9 \\
Child's HbAlc & $9.2(1.4)$ & $7.1(0.5)$ \\
Child's time since T1D diagnosis, months & $55(33.8)$ & $53.4(28.5)$ \\
\hline
\end{tabular}

Note. $\mathrm{PDC}=$ Poor diabetes control; $\mathrm{GDC}=$ good diabetes control; HbA1c $=$ glycated hemoglobin; $\mathrm{T} 1 \mathrm{D}=$ type 1 diabetes. 
The mean age of the mothers was 40 years $(S D=7.8)$ in the GDC group and 38 years $(S D=6)$ in the PDC group. Children were on average 10 years old in both groups $(S D=1.8$ and 2.1, respectively). There were no significant differences in the demographic features of mothers and children between the groups (see Table 1). The average time since T1D diagnosis was 54 months in the GDC group and 55 months in the PDC group. HbA1c levels were $M=7.1(S D=$ $0.5)$ in the GDC group and $M=9.2(S D=1.4)$ in the PGC group.

\section{Measures}

Mothers' reflective functioning. The Spanish version (Golano-Fornells, Perez-Testor, and Salamero-Baro, 2018) of the PDI-Reflective Functioning Scale (RFS) (Fonagy et al., 1998; Slade et al., 2005) as scored on the Parental Development Interview (PDI; Aber, Slade, Berger, Bresgi, and Kaplan, 1985; Slade, Aber, Bresgi, Berger, and Kaplan, 2004) was used to assess the mothers' RF. The PDI is a 45-item interview that examines parents' representations of their children, themselves as a parent, and their relationship with their children. Interviewees are asked to provide real-life examples of their child's behavior, thoughts, and feelings, which illustrate their understanding of their own and their child's internal experience. For the present study, interviews were carried out by the first and fourth authors (SC and FM). SC is certified in administering the PDI and supervised the other interviewer. Maternal RF was measured using the PDI-RFS (Fonagy et al., 1998; Slade et al., 2005), a coding scale that was adapted from the RFS, which was initially developed to be scored with the Adult Attachment Interview. The RFS employs an 11-point scale using a manual that provides illustrations of different types and levels of RF responses, ranging from 1 (avoidance or active refusal to mentalize) to 9 (exceptionally 
rich, complete, and sophisticated understanding of mental states in interaction). An overall RF score was assigned following the guidelines in the manual (see Figure 2).

\begin{tabular}{|c|c|}
\hline & \\
\hline $\begin{array}{l}-1 \text { Negative } \\
\text { RF }\end{array}$ & $\begin{array}{l}\text { Anti-reflective; bizarre; hostile; inappropriate "Why are } \\
\text { you asking if I get angry? You're just trying to find bad } \\
\text { things against me" }\end{array}$ \\
\hline $\begin{array}{c}0 \\
1 \text { Absent RF }\end{array}$ & $\begin{array}{l}\text { Passively evasive; little or no hostility; disavowal } \\
\text { explanations "I don't know. I really couldn't say" }\end{array}$ \\
\hline 2 & \\
\hline $\begin{array}{l}3 \\
\text { Questionable } \\
\text { or low RF } \\
4\end{array}$ & $\begin{array}{l}\text { Uses mental state language but not reflectively; superficial; } \\
\text { clichéd "She just wants this and wants that" }\end{array}$ \\
\hline $\begin{array}{l}5 \text { Definite or } \\
\text { ordinary } R F \\
\quad 6\end{array}$ & $\begin{array}{l}\text { Uses non-clichéd mental state language reflectively "I think } \\
\text { he felt sad and that's why he started clinging to me" }\end{array}$ \\
\hline 7 Marked RF & $\begin{array}{l}\text { Sophisticated RF on mental states more than once but not } \\
\text { continually; complex; an interactive perspective "She was } \\
\text { so happy and kept cuddling up and kissing me, and that } \\
\text { made me happy" }\end{array}$ \\
\hline $\begin{array}{l}8 \\
9 \text { Full or } \\
\text { exceptional } \\
\text { RF }\end{array}$ & Full awareness of reflecting on mental states; sophisticated \\
\hline
\end{tabular}

\section{Figure 2. Examples of Scores on Parental Reflective Functioning}

Taken from Fonagy, Target, Steele and Steele (1998)

Reliability estimates of the RFS as scored on the PDI have been shown to be good, with internal consistencies ranging from .78 to .95 (Slade, Grienenberger, Bernbach, Levy, and Locker, 2005). In this study, all interviews were coded by two trained and certified Spanishspeaking raters. Both raters were blind to whether children belonged to the GDC or PDC group. Moreover, the interviews carried out by the author were coded by the second rater, and vice versa, in order to avoid bias.

Inter-rater reliability between the two independent raters was calculated on 10 randomly selected interviews using the intra-class coefficient (ICC) based on an absolute agreement and two-way mixed-effect model. ICC values were .83 (CI .42-.96) for single measures and .91 (CI: 
.66-.98) for average measures. These results indicate a good level of reliability (Portney and Watkins, 2000).

Children's reflective functioning. The Chilean version (Lecannelier, unpublished manuscript) of the Child Reflective Functioning Scale (CRFS; Ensink et al., 2013) was used to rate child RF on the Child Attachment Interview (CAI; Shmueli-Goetz et al., 2008; Target, Fonagy, Shmueli-Goetz et al., 2000). The CAI is a semi-structured interview for 8- to 12-yearolds consisting of 13 questions. It was developed to assess children's attachment representations of their current relationships with primary caregivers. Children are asked to give adjectives to describe themselves and their attachment relationships. This is followed by requests for examples to illustrate why they chose these adjectives. For example, children are asked the following questions: "Can you think of three words to describe your relationship with your mum?” For each word that the child gives, they are asked: "Can you give me an example that illustrates why you picked that word; of a time when your relationship was (e.g., loving)?” and: “Can you think of a time when your mum got angry with you? Tell me what happened." After each question children are asked about why they think the parents behaved in the way they did, how that made them feel, and how they think their parents felt.

The CRFS was developed to assess RF in middle childhood, rating the data gathered using the CAI based on the Adult Reflective Functioning Manual developed by Fonagy, Target, Steele, and Steele (1998), with modifications addressing the developmental characteristics of children aged 8 to 12 years. Children's responses are coded on an 11-point scale ranging from -1 to 9 , in terms of the child's ability to give an account of his or her capacity to make meaning of 
personal and interpersonal behaviors and interactions based on underlying mental states. The

CRFS has shown high inter-rater reliability, with a median ICC of .93 (Ensink et al., 2013).

In the present study, child RF was rated by the first (SC) and third (DC) authors. DC is a certified CRFS rater and supervised the first rater. Inter-rater reliability was calculated between both raters on 10 randomly selected CAIs. Again, both raters were blind to whether children belonged to the GDC or PDC group, and the interviews carried out by the first rater were coded by the second rater and vice versa in order to avoid bias. ICC estimates and $95 \%$ confidence intervals were calculated based on an absolute-agreement and two-way mixed-effects model. The obtained ICC value was .97 (CI .87-.99) for single measures and .98 (CI .93-.99) for average measures, indicating an excellent level of reliability (Portney and Watkins, 2000). In this study, child RF was highly positively correlated with maternal RF $(r=.84, p<.001)$ in the whole sample.

Subjective stress in children. We used the Chilean version (Caqueo-Urízar, Urzúa, and Osika, 2014) of the Stress in Children (SiC) (Osika et al., 2007) scale. The SiC is a 21-item questionnaire for school-age children designed to assess perceived distress, levels of well-being, and aspects of coping and social support. Participants are asked to rate how often they felt or thought a certain way during the past month, ranging from never to very often, with higher scores indicating higher levels of stress. The SiC has demonstrated high internal consistency, with a Cronbach's alpha coefficient of .79 for the complete test score and $.79, .67$, and .62 for the three subscales (lack of well-being, distress, and lack of social support), respectively. The SiC has also been shown to be reliable in the Chilean population (Caqueo-Urízar et al., 2014). In this study, 
internal consistencies for each scale were $\alpha=.75, .70$, and.70, for lack of well-being, distress and lack of social support, respectively.

Diabetes outcomes. The children's diabetes-specific quality of life was measured using the Latin-American version of the Pediatric Quality of Life Inventory Diabetes Module 3.2 Parent-Report (PedsQL 3.2 Diabetes Module; Varni et al., 2003). This scale assesses the parent's view of how well the illness has been integrated into the child's life, and concerns several dimensions of diabetes care, which are reflected in each of the subscales. In this sense, the PedsQL can be considered an indicator of diabetes outcomes. the PedsQL consists of 28 items divided into four subscales: (1) Absence of Symptoms (AS; 11 items; e.g., in the past month "It has been a problem for my child feeling dizzy”), (2) Treatment Adherence (TA; 11 items; e.g., in the past month "It has been a problem for my child to follow his diabetes treatment), (3) Absence of Concerns (ACr; 3 items; e.g., in the past month "It has been a problem for my child being worried about future diabetes complications"), and (4) Diabetes Communication (DCm; 3 items; e.g., in the past month "It has been a problem for my child to explain his illness to other people"). Higher scores reflect higher diabetes-specific quality of life. Studies suggest acceptable to excellent internal consistencies of all subscales. In the present study, the Cronbach's alpha of the PedsQL total score was $\alpha=.80$ and the subscales' $\alpha$ coefficients were .77 (AS), .71 (TA), .70 (ACr), and .71 (DCm).

Diabetes control. Measurements of $\mathrm{HbA1c}$ were used to assess diabetes control. Each HbA1c measurement indicates the average blood glucose levels during the past 90-120 days. HbA1c is considered to be the main indicator of glycemic control (DiMeglio et al., 2018). A 
common target level of HbA1c is below 7, and values above 7.5 are considered to represent a risk of complications (NICE, 2015; American Diabetes Association, 2019).

For this study we asked the mothers to report the results of the children's three most recent $\mathrm{HbA1c}$ measurements. For the purposes of our analyses, we used the average score across these three measurements as an index of diabetes control.

\section{Analyses}

Participants were separated into two groups using a median split based on HbA1c levels. The GDC group comprised participants with a mean HbA1c level below 7.70. Participants with a mean HbA1c level above 7.71 were placed in the PDC group.

First, Pearson correlations between study variables and demographics were computed in order to identify potential covariates. Second, a multivariate analysis of variance (MANOVA) was used to compare maternal RF, child RF, and child stress between the GDC and the PDC groups, followed by univariate analyses of variance (ANOVAs) for each dependent variable. Third, Pearson correlations were performed between the study variables in the total sample.

\section{Results}

\section{Group Differences}

Mothers in the GDC group had significantly higher levels of RF than mothers in the PDC group $(M=5.3, S D=1.5$, and $M=4.4, S D=1.0$, respectively $)$, representing a large effect size (Cohen's $d=.70$ ) (see Table 2). A score of 5 in the RFS is considered to indicate "ordinary" RF and is often found in community samples (Slade et al., 2005), whereas a score of 4 is considered to represent "clichéd" or superficial RF. 
Similarly, children in the GDC group showed higher levels of RF than children in the PDC group $(M=5.0, S D=1.3$, and $M=4.0, S D=1.4$, respectively $)$, again with a large effect size (Cohen's $d=.74$ ) (see Table 2). Yet, although a score of 4 reflects superficial RF, levels of child RF in the PDC were higher than those found in previous studies in community samples (e.g., $M=3.25$ in Ensink et al., 2014, and $M=3$ in Ensink et al., 2016).

The difference between the two groups on the combined dependent variables was statistically significant $(F(2,52)=4.00, p<.005)$. MANOVA results were followed up with univariate one-way ANOVA for each dependent variable, which revealed statistically significant differences between the GDC and PDC groups in child RF and also in maternal $\operatorname{RF}(F(1,53)=$ 7.762, $p<.01$; partial $\eta^{2}=.128$, and $F(1,53)=6.476, p<.05$; partial $\eta^{2}=.109$, respectively). In addition, univariate ANOVAs revealed, as expected, a significant positive effect of child RF on diabetes-specific quality of life $(F(1,53)=7.76, p<.01)$ and of maternal RF on diabetes outcomes $(F(1,53)=6.47, p<.05)$. Finally, contrary to expectations, boys in the PDC group did not report significantly higher scores on stress than boys in the GDC group $(p=0.6)$.

Table 2. Group Comparisons for Maternal and Child Reflective Functioning (RF) in 55 Mother-Child Dyads

\begin{tabular}{lllll}
\hline Variable & Group & Mean & SD & F \\
\hline Maternal RF & GDC & 5.3 & 1.5 & $6.476^{*}$ \\
& PDC & 4.4 & 1.0 & \\
\multirow{2}{*}{ Child RF } & GDC & 5.0 & 1.3 & $7.762^{* *}$ \\
& PDC & 4.0 & 1.4 &
\end{tabular}

Note: $* p<.05 ; * * p<.01 ; \mathrm{PDC}=$ Poor diabetes control; GDC= good diabetes control.

\section{Correlations Between Study Variables}

Child RF and maternal RF were highly significantly correlated $(r=.793, p<.01)$. As expected, both child and maternal RF were negatively correlated with $\mathrm{HbA1c}(r=-.352, p=$ .005 , and $r=-.339, p=.006$, respectively; see Table 3). However, only child RF showed a 
positive correlation with PedsQL absence of symptoms $(r=.226, p=.049)$. Moreover, maternal RF was negatively correlated with diabetes communication, which was unexpected $(r=-.302, p$ $=.013)$.

Children's stress was, as expected, negatively correlated with maternal RF $(r=-.239, p=$ .043), but not with child RF. Finally, stress in children was not correlated with HbA1c, but was negatively correlated with the absence of symptoms, absence of concerns, treatment adherence, and the total diabetes quality of life score.

Table 3

Summary of Intercorrelations, Means, and Standard Deviation for Scores on the RFS, HbA1c, PEDSQL, and $\mathrm{SiC}$ in the total sample $(\mathrm{n}=55)$

\begin{tabular}{|c|c|c|c|c|c|c|c|c|c|c|}
\hline Variable & 1 & 2 & 3 & 4 & 5 & 6 & 7 & 8 & $\mathrm{M}$ & SD \\
\hline 1.Child RF & - & & & & & & & & 4.2 & 1.4 \\
\hline $\begin{array}{l}\text { 2.Maternal } \\
\text { RF }\end{array}$ & $.793 * *$ & - & & & & & & & 4.6 & 1.5 \\
\hline 3. $\mathrm{HbA} 1 \mathrm{c}$ & $-.352^{* *}$ & $-.339 * *$ & - & & & & & & 8.0 & 1.5 \\
\hline $\begin{array}{l}\text { 4.Pedsql } \\
\text { Communic } \\
\text { ation } \\
\text { 5.Pedsql }\end{array}$ & -.214 & $-.302^{*}$ & -.178 & - & & & & & 3.2 & .99 \\
\hline $\begin{array}{l}\text { Absence of } \\
\text { Symptoms } \\
6 . \text { Pedsql }\end{array}$ & $.226 *$ & -.250 & $-.451^{* *}$ & .143 & - & & & & 3.1 & .70 \\
\hline $\begin{array}{l}\text { Absence of } \\
\text { Concerns } \\
\text { 7. Pedsql }\end{array}$ & .210 & .207 & -.200 & .172 & $.346^{* *}$ & - & & & 3.0 & 1.0 \\
\hline $\begin{array}{l}\text { Treatment } \\
\text { Adherence }\end{array}$ & .136 & .201 & $-.507^{* *}$ & $.334 * *$ & $.646^{* *}$ & $.368^{* *}$ & - & & 3.1 & .89 \\
\hline $\begin{array}{l}\text { 8. Pedsql } \\
\text { Total score }\end{array}$ & .157 & .200 & $-.510 * *$ & $.459 * *$ & $.857^{* *}$ & $.581^{* *}$ & $.873^{* *}$ & - & 3.3 & .64 \\
\hline 9. SiC & -.001 & $-.239 *$ & .089 & .081 & $-.375^{* *}$ & -.209 & $-.410 * *$ & $-.375^{* *}$ & 5.6 & 2.8 \\
\hline
\end{tabular}

Note. For all scales, higher scores are indicative of more extreme responding in the direction of the construct assessed. For HbA1c levels, higher scores are indicative of suboptimal diabetes control. RFS= Reflective Functioning Scale; HbA1c= Glycated Haemoglobin; Pedsql=Pediatric Diabetes Specific Quality of Life; $\mathrm{SiC}=$ Stress in Children.

$* \mathrm{p}<.05 ; * * \mathrm{p}<.01$ 


\section{Discussion and Conclusions}

We investigated the relationships between child RF, maternal RF, and children's stress levels and diabetes outcomes by comparing groups of boys with good and poor diabetes control. Moreover, we examined associations between maternal RF, child RF, children's levels of stress, and children's diabetes outcomes. We expected to find higher levels of both maternal and child RF, and lower children's stress levels, in the GDC group than in the PDC group. We also hypothesized that both maternal RF and child RF would be negatively correlated with HbA1c, and positively correlated with diabetes-specific quality of life. Finally, we expected children's stress levels to be negatively correlated with maternal RF, child RF, and diabetes-specific quality of life, and positively correlated with HbA1c.

Results partially supported our hypotheses. First, levels of both maternal RF and child RF were significantly higher in the GDC group than the PDC group. Furthermore, both child and maternal RF were negatively correlated with $\mathrm{HbA} 1 \mathrm{c}$, an objective index of diabetes control. Moreover, child RF was associated with lower levels of diabetes-related symptoms.

However, surprisingly, there were no statistically significant differences between groups in children's stress levels, although children's stress was negatively associated with maternal RF and positively with diabetes symptoms, implying that higher maternal RF might be associated with lower levels of stress in the child, and that high stress in boys with diabetes may be related to poorer diabetes outcomes. The differences in RF between the two groups suggest that higher RF might be related to better diabetes outcomes. Additionally, the negative association between maternal RF and children's stress suggests a role of parental mentalizing in diabetic children's stress regulation. Yet, it may be that poor diabetes outcomes negatively influence RF in both children and mothers, which in turn affects diabetes control, and the dyad may become trapped 
in a vicious cycle. Conversely, GDC may foster mentalizing in both mothers and children. Further longitudinal research is needed in this regard to identify causality in the observed association between child and maternal RF and diabetes outcome. Yet, findings of this study are consistent with previous studies showing that higher levels of mentalizing are associated with resilience (Fonagy et al., 1994; Ensink, Begin, Normandin, and Fonagy, 2016; Ensink, Normandin, Target, Fonagy, Sabourin and Berthelot, 2015).

Specifically, it has been argued that mentalizing is an important mechanism involved in stress regulation (Luyten and Fonagy, 2016). Impairments in stress regulation, especially those associated with dysregulation of the HPA axis, have been shown to be a key factor in a wide array of somatic and functional somatic conditions (Gunnar and Quevedo., 2007; Muscatell and Eiserberger, 2012; Carroll et al., 2012; Peters, McEwen, and Friston, 2017; Picard and McEwen, 2018). Additionally, parental stress has been reported to be one of the strongest determinants of psychosocial problems in children with diabetes (Drotar, 1997; Hilliard et al., 2011; Kovacs et al., 1997). The activation of the stress response would be partly linked with the experience of threat that the illness entails.

Hence, GDC may entail children being able to reflect on the impact of their illness, instead of relating to diabetes as an internal threat that is felt as attacking the self from within (Shahar and Lerman, 2013). It may be that this process is supported by the child (and parent) mentalizing the illness - that is, understanding how the experience of diabetes is linked with mental states. For example, reflecting on the impact of diabetes on identity, differentiating hyperglycemic states from emotional states or identifying the effect of certain mental states on blood glucose levels. 
Moreover, in childhood, the understanding of minds develops within attachment relationships (Stern, 1985; Allen, 2013, Fonagy et al., 2002); similarly, diabetic management in children is also performed in coordination with caregivers. Hence, good diabetic control may rely not only on children's own capacity for mentalizing, but also on that of their caregivers. It has been proposed that the caregiver's ability to regulate his/her own stress level has an important influence on the child's strategies for stress regulation (Nolte et al., 2011). However, even effective strategies for the regulation of stress can fail in the face of chronic activation of stress (Luyten et al., 2012), as may occur in a parent faced with their child's chronic illness.

Hence, in order to understand the reflective process by which the child integrates diabetes into his/her internal psychological world, it may be essential to include the caregiver's ability to understand his/her own mind as that of his/her child. The results presented here provide further support for these assumptions, as maternal RF was associated with diabetes outcomes in the children.

Surprisingly, there were no significant differences in subjective stress reported by boys in the GDC and PDC groups. This rather contradictory finding may perhaps be explained by reporting bias, particularly in boys in the PDC group, as denial of distress is commonly observed in children with avoidant attachment strategies, which is the most common insecure attachment pattern among boys (Finnegan, Hodges and Perry, 1996; Karavasilis, Doyle and Markiewickz, 2003; Del Giudice, 2008). In contrast, HbA1c values were related to both maternal and child RF. Further research is needed to investigate this assumption.

Findings of this study need to be interpreted in the context of a number of important limitations. First, the study focused on boys only, and hence research is needed to investigate whether similar findings are obtained in girls. Second, the relatively small sample size and the 
fact that most mothers were relatively highly educated may partly explain why levels of both maternal RF and child RF were higher in our sample than those found in previous studies with community samples. Third, stress was assessed using a self-report measure. Future studies should include more objective measures of stress, such as cortisol or heart rate variability. Finally, the present study was conducted in Chile, and thus the extent to which these findings can be generalized to other samples and cultures remains to be determined.

Despite these limitations, this study, if replicated, may have important implications for prevention of complications and intervention. Specifically, findings of this study suggest that interventions designed to improve mentalizing in children with T1D and their caregivers may have a positive effect on diabetic control. Furthermore, the finding that both child RF and maternal RF were related to T1D suggests that complication's prevention and intervention efforts should focus on both children with T1D and their caregivers.

In conclusion, the present study provides further support for the value of contemporary attachment and mentalization-based approaches in the study and clinical management of T1D, as both maternal RF and child RF were related to diabetes outcomes. However, further longitudinal research is needed to investigate the interplay between RF in diabetic children and their caregivers in relation to diabetes outcomes over time. Furthermore, future research is needed to study the psychological and biological mechanisms involved in these associations. 


\section{References}

Aber, J. L., Slade, A., Berger, B., Bresgi, I., \& Kaplan, M. (1985). The parent development interview. Unpublished manuscript.

Allen, J. G. (2013). Mentalizing in the development and treatment of attachment trauma. London, England: Karnac Books.

American Diabetes Association (ADA). (2017). 2. Classification and diagnosis of diabetes. Diabetes care, 40 (Supplement 1), S11-S24.

American Diabetes Association. (2019). 6. Glycemic targets: standards of medical care in diabetes-2019. Diabetes Care, 42 (Supplement 1), S61-S70.

Bartholomew, K., \& Horowitz, L. M. (1991). Attachment styles among young adults: a test of a four-category model. Journal of personality and social psychology, 61(2), 226.

Bazzazian, S., \& Besharat, M. A. (2012). An explanatory model of adjustment to type I diabetes based on attachment, coping, and self-regulation theories. Psychology, health \& medicine, 17(1), 47-58.

Bearman, K. J., \& La Greca, A. M. (2002). Assessing friend support of adolescents' diabetes care: The Diabetes Social Support Questionnaire-Friends Version. Journal of Pediatric Psychology, 27(5), 417-428. https://doi.org/10.1093/jpepsy/27.5.417.

Bowlby, J. (1969). Attachment and loss v. III (Vol. 1). New York: Random House.

Bowlby, J. (1973). Attachment and loss, vol. II: Separation (Vol. 2). New York: Basic Books.

Burroughs, T. E., Harris, M. A., Pontious, S. L., \& Santiago, J. V. (1997). Research on Social Support In Adolescents With IDDM: A Critical Review. The Diabetes Educator, 23(4), 438-448. https://doi.org/10.1177/014572179702300409 
Caqueo-Urízar, A., Urzúa, A., \& Osika, W. (2014). Psychometric properties of the Spanish language version of the stress in children questionnaire (SiC). Psicologia: Reflexão e Crítica, 27(1), 81-89.

Carroll, D., Ginty, A. T., Der, G., Hunt, K., Benzeval, M., \& Phillips, A. C. (2012). Increased blood pressure reactions to acute mental stress are associated with 16-year cardiovascular disease mortality. Psychophysiology, 49(10), 1444-1448. https://doi.org/10.1111/j.1469$\underline{8986.2012 .01463 . \mathrm{x}}$

Cassidy, J., \& Kobak, R. R. (1988). Avoidance and its relation to other defensive processes. In J. Belsky \& T. Nezworski (Eds.), Child psychology. Clinical implications of attachment (pp. 300-323). Hillsdale, NJ, US: Lawrence Erlbaum Associates, Inc.

Ciechanowski, P. S., Katon, W. J., Russo, J. E., \& Walker, E. A. (2001). The patient-provider relationship: attachment theory and adherence to treatment in diabetes. American Journal of Psychiatry, 158(1), 29-35.

Ciechanowski, P. S., Hirsch, I. B., \& Katon, W. J. (2002). Interpersonal Predictors of HbA1c in Patients With Type 1 Diabetes. Diabetes Care, 25(4), 731-736. doi:10.2337/diacare.25.4.731

Ciechanowski, P., Russo, J., Katon, W., Von Korff, M., Ludman, E., Lin, E., ... \& Bush, T. (2004). Influence of patient attachment style on self-care and outcomes in diabetes. Psychosomatic Medicine, 66(5), 720-728.

Collins, N. L., \& Read, S. J. (1990). Adult attachment, working models, and relationship quality in dating couples. Journal of personality and social psychology, 58(4), 644.

Daneman, D., \& Daneman, M. (2012). What has attachment theory got to do with diabetes care? Diabetes Management, 2(2), 85-87. doi:10.2217/dmt.12.5 
Delamater, A. M., de Wit, M., McDarby, V., Malik, J. A., Hilliard, M. E., Northam, E., \& Acerini, C. L. (2018). ISPAD Clinical Practice Consensus Guidelines 2018: Psychological care of children and adolescents with type 1 diabetes. Pediatric Diabetes, 19 Suppl 27, 237-249. https://doi.org/10.1111/pedi.12736

Diamond, L. M., \& Aspinwall, L. G. (2003). Emotion regulation across the life span: An integrative perspective emphasizing self-regulation, positive affect, and dyadic processes. Motivation and Emotion, 27(2), 125-156.

DiMeglio, L. A., Evans-Molina, C., \& Oram, R. A. (2018). Type 1 diabetes. The Lancet, 391(10138), 2449-2462. doi:10.1016/s0140-6736(18)31320-5

Drotar, D. (1997). Relating parent and family functioning to the psychological adjustment of children with chronic health conditions: what have we learned? What do we need to know? Journal of Pediatric Psychology, 22(2), 149-165.

https://doi.org/10.1093/jpepsy/22.2.149

Ensink, K., Bégin, M., Normandin, L., \& Fonagy, P. (2016). Maternal and child reflective functioning in the context of child sexual abuse: pathways to depression and externalising difficulties. European Journal of Psychotraumatology, 7(1), 30611. doi:10.3402/ejpt.v7.30611

Ensink, K., Berthelot, N., Bernazzani, O., Normandin, L., \& Fonagy, P. (2014). Another step closer to measuring the ghosts in the nursery: preliminary validation of the Trauma Reflective Functioning Scale. Frontiers in psychology, 5, 1471.

Ensink, K., Normandin, L., Target, M., Fonagy, P., Sabourin, S., \& Berthelot, N. (2014). Mentalization in children and mothers in the context of trauma: An initial study of the validity of the Child Reflective Functioning Scale. British Journal of Developmental Psychology, 33(2), 
203-217. doi:10.1111/bjdp.12074

Ensink, K., Target, M., \& Oandasan, C. (2013). Child reflective functioning scale scoring manual: For application to the child attachment interview. Unpublished manuscript.

Fazeli Farsani, S., Souverein, P. C., van der Vorst, M. M., Knibbe, C. A., Herings, R. M., de Boer, A., \& Mantel-Teeuwisse, A. K. (2016). Increasing trends in the incidence and prevalence rates of type 1 diabetes among children and adolescents in the Netherlands. Pediatric diabetes, 17(1), 44-52.

Finnegan, R. A., Hodges, E. V. E., \& Perry, D. G. (1996). Preoccupied and avoidant coping during middle childhood. Child Development, 67(4), 1318-1328.

http://dx.doi.org/10.2307/1131702

Fonagy, P., \& Bateman, A. W. (2006). Mechanisms of change in mentalization-based treatment of BPD. Journal of Clinical Psychology, 62, 411-430

Fonagy, P., \& Bateman, A. W. (2008). The development of borderline personality disorder-A mentalizing model. Journal of Personality Disorders, 22, 4-21.

Fonagy, P., \& Luyten, P. (2009). A developmental, mentalization-based approach to the understanding and treatment of borderline personality disorder. Development and psychopathology, 21(4), 1355-1381.

Fonagy, P., \& Luyten, P. (2016). A Multilevel Perspective on the Development of Borderline Personality Disorder. Developmental Psychopathology, 1-67. doi:10.1002/9781119125556.devpsy317.

Fonagy, P., \& Moran, G. S. (1990). Studies on the efficacy of child psychoanalysis. Journal of Consulting and Clinical Psychology, 58(6), 684.

Fonagy, P., \& Moran, G. S. (1991). Understanding psychic change in child psychoanalysis. 
International Journal of Psycho-Analysis, 72, 15-22.

Hodes, M. \& Moorey, S. (1993). Psychological Treatment in Disease and Illness. London: Gaskell 6r The Society for Psychosomatic Research.

Fonagy, P., \& Moran, G. S. (1994). Psychoanalytic formulation and treatment of chronic metabolic disturbance in insulin dependent diabetes mellitus. London: Whurr Publications.

Fonagy, P., \& Target, M. (2006). The mentalization-focused approach to self pathology. Journal of Personality Disorders, 20, 544-576.

Fonagy, P., Gergely, G., Jurist, E. L., \& Target, M. (2002). Affect Regulation, Mentalization, and the Development of the Self. New York: Yale University Press.

Fonagy, P., Steele, M., Steele, H., Higgitt, A., \& Target, M. (1994). The Emanuel Miller memorial lecture 1992 the theory and practice of resilience. Journal of child psychology and psychiatry, 35(2), 231-257. https://doi.org/10.1111/j.1469-7610.1994.tb01160.x

Fonagy, P., Target, M., Steele, H., \& Steele, M. (1998). Reflective-functioning manual, version 5.0, for application to adult attachment interviews. London: University College London, $161-62$.

Fraley, R. C., \& Shaver, P. R. (1998). Airport separations: A naturalistic study of adult attachment dynamics in separating couples. Journal of personality and Social Psychology, 75(5), 1198.

Gale, E. A., \& Gillespie, K. M. (2001). Diabetes and gender. Diabetologia, 44(1), 3-15.

Giudice, M. (2008). Sex-biased ratio of avoidant/ambivalent attachment in middle childhood. British Journal of Developmental Psychology, 26(3), 369-379. doi:10.1348/026151007x243289 
Golano-Fornells, M., Pérez-Téstor, C., \& Salamero-Baró, M. (2018). The Spanish and Catalan Versions of the Parent Development Interview-Revised (PDI-R): Adaptation and Validation Process. Contemporary Family Therapy, 40(4), 338-345.

Grey, M., Lipman, T., Cameron, M. E., \& Thurber, F. W. (1997). Coping behaviors at diagnosis and in adjustment one year later in children with diabetes. Nursing Research, 46(6), 312317.

Gunnar, M., \& Quevedo, K. (2007). The neurobiology of stress and development. Annu. Rev. Psychol., 58, 145-173.

Hansen, J. A., Weissbrod, C., Schwartz, D. D., \& Taylor, W. P. (2012). Paternal involvement in pediatric Type 1 diabetes: Fathers' and mothers' psychological functioning and disease management. Families, Systems, \& Health, 30(1), 47-59. https://doi.org/10.1037/a0027519

Helgeson, V., Siminerio, L., Escobar, O., \& Becker, D. (2009). Predictors of metabolic control among adolescents with diabetes: A 4-year longitudinal study. Journal of Pediatric Psychology, 34(3), 254-270. https://doi.org/10.1093/jpepsy/jsn079

Hilliard, M. E., Monaghan, M., Cogen, F. R., \& Streisand, R. (2011). Parent stress and child behaviour among young children with type 1 diabetes. Child: Care, Health and Development, 37(2), 224-232. https://doi.org/10.1111/j.1365-2214.2010.01162.x

Hilliard, M. E., Yi-Frazier, J. P., Hessler, D., Butler, A. M., Anderson, B. J., \& Jaser, S. (2016). Stress and A1c Among People with Diabetes Across the Lifespan. Current Diabetes Reports, 16(8), 67. https://doi.org/10.1007/s11892-016-0761-3

Horsch, A., McManus, F., Kennedy, P., \& Edge, J. (2007). Anxiety, depressive, and posttraumatic stress symptoms in mothers of children with type 1 diabetes. Journal of 
Traumatic Stress, 20(5), 881-891. https://doi.org/10.1002/jts.20247

International Diabetes Federation. (2017). IDF Diabetes Atlas, 8th edn. Brussels, Belgium: International Diabetes Federation.

Jönsson, L., Lundqvist, P., Tiberg, I., \& Hallström, I. (2015). Type 1 diabetes - impact on children and parents at diagnosis and 1 year subsequent to the child's diagnosis. Scandinavian Journal of Caring Sciences, 29(1), 126-135. https://doi.org/10.1111/scs.12140.

Karavasilis, L., Doyle, A. B., \& Markiewicz, D. (2003). Associations between parenting style and attachment to mother in middle childhood and adolescence. International Journal of Behavioral Development, 27(2), 153-164. doi:10.1080/0165025024400015

Klahr, A. M., \& Burt, S. A. (2014). Elucidating the etiology of individual differences in parenting: A meta-analysis of behavioral genetic research. Psychological Bulletin, 140(2), 544-586. doi:10.1037/a0034205

Konen, J. C., Summerson, J. H., \& Dignan, M. B. (1993). Family function, stress, and locus of control: relationships to glycemia in adults with diabetes mellitus. Archives of Family Medicine, 2(4), 393.

Koelen, J. A., Eurelings-Bontekoe, E. H., van Broeckhuysen-Kloth, S. A., Snellen, W. M., \& Luyten, P. (2014). Social cognition and levels of personality organization in patients with somatoform disorders: A case-control study. The Journal of nervous and mental disease, 202(3), 217-223.

Kongkaew, C., Jampachaisri, K., Chaturongkul, C. A., \& Scholfield, C. N. (2014). Depression and adherence to treatment in diabetic children and adolescents: a systematic review and meta-analysis of observational studies. European journal of pediatrics, 173(2), 203-212. 
http://doi.org/10.1007/s00431-013-2128-y.

Kovacs, M., Goldston, D., Obrosky, D., \& Bonar, L. (1997). Psychiatric disorders in youths with IDDM: rates and risk factors. Diabetes Care, 20(1), 36-44. https://doi.org/10.2337/diacare.20.1.36.

La Greca, A. M., Swales, T., Klemp, S., Madigan, S., \& Skyler, J. (1995). Adolescents with diabetes: Gender differences in psychosocial functioning and glycemic control. Children's Health Care, 24(1), 61-78. https://doi.org/10.1207/s15326888chc2401_6.

Landolt, M. A. et al., (2002). Posttraumatic Stress Disorder in Parents of Children With Newly Diagnosed Type 1 Diabetes. Journal of Pediatric Psychology, 27(7), 647-652. doi:10.1093/jpepsy/27.7.647

Landolt, M. A., Vollrath, M., Laimbacher, J., Gnehm, H. E., \& Sennhauser, F. H. (2005). Prospective Study of Posttraumatic Stress Disorder in Parents of Children With Newly Diagnosed Type 1 Diabetes. Journal of the American Academy of Child \& Adolescent Psychiatry, 44(7), 682-689. doi:10.1097/01.chi.0000161645.98022.35.

Lecannelier, F. (2010). La Entrevista de Apego Infantil. Unpublished Manuscript.

Lind, M., Pivodic, A., Svensson, A.-M., Ólafsdóttir, A. F., Wedel, H., \& Ludvigsson, J. (2019). HbA1c level as a risk factor for retinopathy and nephropathy in children and adults with type 1 diabetes: Swedish population based cohort study. BMJ, 14894. doi:10.1136/bmj.14894

Lloyd, C. E., Dyer, P. H., Lancashire, R. J., Harris, T., Daniels, J. E., \& Barnett, A. H. (1999). Association between stress and glycemic control in adults with type 1 (insulin-dependent) diabetes. Diabetes Care, 22(8), 1278-1283. https://doi.org/10.2337/diacare.22.8.1278.

Lohan, A., Morawska, A., \& Mitchell, A. (2015). A systematic review of parenting interventions 
for parents of children with type 1 diabetes. Child: Care, Health and Development, 41(6), 803-817. doi:10.1111/cch.12278

Luyten, P., \& Fonagy, P. (2015). The neurobiology of mentalizing. Personality Disorders: Theory, Research, and Treatment, 6(4), 366-379. doi:10.1037/per0000117

Luyten, P., \& Fonagy, P. (2016). An integrative, attachment-based approach to the management and treatment of patients with persistent somatic complaints. In Improving Patient Treatment with Attachment Theory (pp. 127-144). Springer, Cham.

Luyten, P., Van Houdenhove, B., Lemma, A., Target, M., \& Fonagy, P. (2012). A mentalizationbased approach to the understanding and treatment of functional somatic disorders. Psychoanalytic Psychotherapy, 26(2), 121-140.

Luyten, P., Van Houdenhove, B., Lemma, A., Target, M., \& Fonagy, P. (2013). Vulnerability for functional somatic disorders: A contemporary psychodynamic approach. Journal of Psychotherapy Integration, 23(3), 250.

Malberg, N. T. (2013). Mentalization based group interventions with chronically ill adolescents: An example of assimilative psychodynamic integration?. Journal of Psychotherapy Integration, 23(1), 5.

McEwen, B. S. (2007). Physiology and neurobiology of stress and adaptation: central role of the brain. Physiological reviews, 87(3), 873-904.

Meins, E., Fernyhough, C., Fradley, E., \& Tuckey, M. (2001). Rethinking maternal sensitivity: Mothers' comments on infants' mental processes predict security of attachment at 12 months. The Journal of Child Psychology and Psychiatry and Allied Disciplines, 42(5), 637-648.

Mikulincer, M., \& Florian, V. (1995). Appraisal of and coping with a real-life stressful situation: 
The contribution of attachment styles. Personality and Social Psychology Bulletin, 21(4), 406-414.

Mikulincer, M., \& Shaver, P. R. (2007). Boosting attachment security to promote mental health, prosocial values, and inter-group tolerance. Psychological Inquiry, 18(3), 139156.

Moran, G. S., \& Fonagy, P. (1987). Psychoanalysis and diabetic control: A single-case study. British Journal of Medical Psychology, 60(4), 357-372.

Moran, G., Fonagy, P., Kurtz, A., Bolton, A., \& Brook, C. (1991). A controlled study of the psychoanalytic treatment of brittle diabetes. Journal of the American Academy of Child \& Adolescent Psychiatry, 30(6), 926-935. https://doi.org/10.1097/0000458319911100000010.

Morris, L., Berry, K., Wearden, A. J., Jackson, N., Dornan, T., \& Davies, R. (2009). Attachment style and alliance in patients with diabetes and healthcare professionals. Psychology, health \& medicine, 14(5), 585-590.

Muscatell, K. A., \& Eisenberger, N. I. (2012). A social neuroscience perspective on stress and health. Social and personality psychology compass, 6(12), 890-904.

Naar-King, S., Podolski, C. L., Ellis, D. A., Frey, M. A., \& Templin, T. (2006). Social ecological model of illness management in high-risk youths with type 1 diabetes. Journal of Consulting and Clinical Psychology, 74(4), 785. http://dx.doi.org/10.1037/0022006X.74.4.785

National Collaborating Centre for Women's and Children's Health (UK). National Institute for Health and Care Excellence. (2015). Diabetes (Type 1 and Type 2) in Children and Young People: Diagnosis and Management. (NICE Quality Standard No. 18). Retrieved from https://www.nice.org.uk/guidance/ng18 
Nolte, T., Guiney, J., Fonagy, P., Mayes, L. C., \& Luyten, P. (2011). Interpersonal stress regulation and the development of anxiety disorders: an attachment-based developmental framework. Frontiers in behavioral neuroscience, 5, 55.

Northam, E., Anderson, P., Adler, R., Werther, G., \& Warne, G. (1996). Psychosocial and family functioning in children with insulin-dependent diabetes at diagnosis and one year later. Journal of Pediatric Psychology, 21(5), 699-717. https://doi.org/10.1093/jpepsy/21.5.699.

Oppenheim, D., \& Koren-Karie, N. (2002). Mothers' insightfulness regarding their children's internal worlds: The capacity underlying secure child-mother relationships. Infant Mental Health Journal: Official Publication of The World Association for Infant Mental Health, 23(6), 593-605.

Osika, W., Friberg, P., \& Wahrborg, P. (2007). A new short self-rating questionnaire to assess stress in children. International journal of behavioral medicine, 14(2), 108-117.

Patterson, C. C., Dahlquist, G. G., Gyürüs, E., Green, A., \& Soltész, G. (2009). Incidence trends for childhood type 1 diabetes in Europe during 1989-2003 and predicted new cases 200520: a multicentre prospective registration study. The Lancet, 373(9680), 2027-2033. https://doi.org/10.1016/S0140-6736(09)60568-7.

Peters, A., McEwen, B. S., \& Friston, K. (2017). Uncertainty and stress: Why it causes diseases and how it is mastered by the brain. Progress in Neurobiology, 156, 164-188. doi:10.1016/j.pneurobio.2017.05.004

Picard, M., \& McEwen, B. S. (2018). Psychological stress and mitochondria: a conceptual framework. Psychosomatic medicine, 80(2), 126.

doi:10.1016/j.pneurobio.2017.05.004 
Portney, L. G., \& Watkins, M. P. (2009). Foundations of clinical research: applications to practice (Vol. 892). Upper Saddle River, NJ: Pearson/Prentice Hall.

Sbarra, D. A., \& Hazan, C. (2008). Coregulation, dysregulation, self-regulation: An integrative analysis and empirical agenda for understanding adult attachment, separation, loss, and recovery. Personality and Social Psychology Review, 12(2), 141-167.

Schönenberg, M., Mares, L., Smolka, R., Jusyte, A., Zipfel, S., \& Hautzinger, M. (2014). Facial affect perception and mentalizing abilities in female patients with persistent somatoform pain disorder. European Journal of Pain, 18(7), 949-956. https://doi.org/10.1002/j.1532-

\subsubsection{0.x}

Shahar, G., \& Lerman, S. F. (2013). The personification of chronic physical illness: Its role in adjustment and implications for psychotherapy integration. Journal of Psychotherapy Integration, 23(1), 49-58. http://dx.doi.org/10.1037/a0030272

Shmueli-Goetz, Y., Target, M., Fonagy, P., \& Datta, A. (2008). The Child Attachment Interview: A psychometric study of reliability and discriminant validity. Developmental psychology, 44(4), 939.

Slade, A., Aber, J. L., Bresgi, I., Berger, B., \& Kaplan, M. (2004). The parent development interview-revised. Unpublished protocol. The City University of New York.

Slade, A., Grienenberger, J., Bernbach, E., Levy, D., \& Locker, A. (2005). Maternal reflective functioning, attachment, and the transmission gap: A preliminary study. Attachment \& Human Devlopment, 7(3), 283-298.

Stern, D. N. (1985). The interpersonal world of the infant: A view from psychoanalysis and developmental psychology. New York: Karnac Books.

Streisand, R., Mackey, E. R., Elliot, B. M., Mednick, L., Slaughter, I. M., Turek, J., \& Austin, A. 
(2008). Parental anxiety and depression associated with caring for a child newly diagnosed with type 1 diabetes: Opportunities for education and counseling. Patient Education and Counseling, 73(2), 333-338. https://doi.org/10.1016/j.pec.2008.06.014.

Sullivan-Bolyai, S., Deatrick, J., Gruppuso, P., Tamborlane, W., \& Grey, M. (2003). Constant vigilance: Mothers' work parenting young children with type 1 diabetes. Journal of Pediatric Nursing, 18(1), 21-29. https://doi.org/10.1053/jpdn.2003.4.

Target, M., Fonagy, P., Shmueli-Goetz, Y., Schneider, T., \& Datta, A. (2000). Child Attachment Interview (CAI): Coding and classification manual. Version III. Unpublished manuscript.

Turan, B., Osar, Z., Turan, J. M., Ilkova, H., \& Damci, T. (2003). Dismissing attachment and outcome in diabetes: The mediating role of coping. Journal of Social and Clinical Psychology, 22(6), 607-626.

Varni, J. W., Burwinkle, T. M., Jacobs, J. R., Gottschalk, M., Kaufman, F., \& Jones, K. L. (2003). The PedsQL ${ }^{\mathrm{TM}}$ in type 1 and type 2 diabetes: reliability and validity of the Pediatric Quality of Life Inventory ${ }^{\mathrm{TM}}$ generic core scales and type 1 diabetes module. Diabetes care, 26(3), 631-637.

Waller, E., \& Scheidt, C. E. (2006). Somatoform disorders as disorders of affect regulation: A development perspective. International Review of Psychiatry, 18(1), 13-24. doi:10.1080/09540260500466774

Wandell, P. E., \& Carlsson, A. C. (2013). Time trends and gender differences in incidence and prevalence of type 1 diabetes in Sweden. Current diabetes reviews, 9(4), 342-349.

Wennick, A., \& Hallström, I. (2007). Families' lived experience one year after a child was diagnosed with type 1 diabetes. Journal of Advanced Nursing, 60(3), 299-307. https://doi.org/10.1111/j.1365-2648.2007.04411.x. 
Zeegers, M. A. J., Colonnesi, C., Stams, G.-J. J. M., \& Meins, E. (2017). Mind matters: A metaanalysis on parental mentalization and sensitivity as predictors of infant-parent attachment. Psychological Bulletin, 143(12), 1245-1272. https://doi.org/10.1037/bul000011 